\title{
ABA REGULATION OF ANTIOXIDANT ACTIVITY DURING POST-GERMINATION DESICCATION AND SUBSEQUENT REHYDRATION IN WHEAT
}

\author{
Satinder Kour* and Vikramit Kaur Zhawar \\ Department of Biochemistry, College of Basic Sciences \& Humanities, Punjab Agricultural University, \\ Ludhiana, 141004, India
}

(Received: March 8, 2018; accepted: June 14, 2018)

\begin{abstract}
$\mathrm{ABA}$ regulation of antioxidant activity during post-germination desiccation and subsequent rehydration was studied in two wheat cultivars PBW 644 (ABA-higher sensitive and drought tolerant) and PBW 343 (ABA-lesser sensitive and drought susceptible) where $1 \mathrm{~d}$-germinated seeds were exposed to ABA/ PEG6000 for next $1 \mathrm{~d}$, desiccated for $4 \mathrm{~d}$ and subsequently rehydrated for $4 \mathrm{~d}$. Ascorbate, dehydrascorbate to ascorbate ratio, malondialdehyde (MDA), hydroxyl radicals, and activities of monodehydroascorbate reductase (MDHAR), dehydroascorbate reductase (DHAR), alcohol dehydrogenase (AlcDH) and aldehyde dehydrogenase (AldDH) were measured in seedlings just before desiccation $(2 \mathrm{~d}$ old $)$, desiccated $(6 \mathrm{~d}$ old $)$ and rehydrated $(10 \mathrm{~d}$ old $)$ stages. ROS/NO signaling was studied under CT and ABA supply by supplying ROS and NO scavengers. During desiccation, both cultivars showed increase of oxidative stress (dehydroascorbate to ascorbate ratio, MDA, hydroxyl radicals) and antioxidant activity in the form of ascorbate content and AldDH activity while other antioxidant enzymes were not increased. PBW 644 showed higher antioxidant activity thus produced less oxidative stress compared to PBW 343. During rehydration, activities of all antioxidant enzymes and levels of ROS (hydroxyl radicals) were increased in both cultivars and MDA was decreased in PBW 343. ABA supply improved desiccation as well as rehydration by improving all parameters of antioxidant activity tested in this study. PEG supply resembled to ABA-supply for its effects. ABA/PEG improvements were seen higher in PBW 644. ROS/ NO-signalling was involved under $\mathrm{CT}$ as well as under $\mathrm{ABA}$ for increasing antioxidant activity during desiccation as well as rehydration in both cultivars.
\end{abstract}

Keywords: Abscissic acid - antioxidant - nitric oxide - post-germination desiccation - reactive oxygen species

\section{INTRODUCTION}

Desiccation tolerance (DT) refers to the ability of a cell to endure loss of all or almost all of its water without irreversible damage. Vegetative DT is not common in angiosperms except resurrection plants $[7,26]$. But angiosperms possess DT in their seeds. Majority of angiosperm species produce orthodox seeds (desiccation tolerant). These seeds acquire DT in the development process during seed maturation and lose DT during germination. Hence studying the dehydration response of seeds during devel-

*Corresponding author; e-mail address: satinder-cobsbcm@pau.edu 
opment and/or germination is a common approach for the study of DT [22]. DT during germination or post-germination-DT is progressively lost until seedlings reach 'point of no return', after this point, seedlings no longer survive desiccation. Study of DT mechanism is very important in plant biology as this knowledge can be applied in many fields like crop breeding programs for improving stress tolerance or productivity, to build DT in recalcitrant seeds of economically important crops, somatic embryos/artificial seeds for their long-time storage $[2,32]$ and many non-plant applications.

Mechanism involved in post-germination-DT is not known but ABA is the main regulator of the response [23-25, 28]. ABA improvement of post-germination-DT is found in Arabidopsis thaliana [28], and in tree species Tabebuia impetiginosa (native tree of tropical America, well adapted to seasonally dry biome) [40], Cedrela fissilis (native tree of Brazilian Atlantic forest) [29]. ABA-insensitive mutants of Arabidopsis thaliana were found impaired in post-germination-DT [28]. ABA may involve its seed-responsive pathways (mediated through ABI3, ABI4, ABI5) to induce DT during germination as reported in $A$. thaliana [23-25]. PEG (inducer of water deficit stress) was also found to improve this DT in tree species [29, 40], A. thaliana [28] and maize [13].

In the present study, post-germination-DT and its improvement by ABA or PEG was studied in wheat. ABA pathways of vegetative stress response (mediated through ABI1 and $\mathrm{ABI}$ ) are different from pathways of its seed responsiveness [5]. ABA-pathways of vegetative stress responsiveness belong to ROS/NO-pathways where ABA produces ROS or NO as secondary signals to activate antioxidant potential [30]. These pathways provide tolerance to different abiotic/biotic stresses [12, 30, 36]. In the present study, ROS/NO-pathways were studied using ROS/NO scavengers under controlled and ABA supplied conditions to check if these contribute to antioxidant activity during post-germination-DT in wheat. Redox state of ascorbate and detoxification enzymes like alcohol dehydrogenase and aldehyde dehydrogenase have been reported as unique components of antioxidant activity under desiccation in resurrection plants [21, 31, 35]. Monodehydroascorbate reductase (MDHAR) and dehydroascorbate reductase (DHAR) enzymes reduce and thus recycle oxidized forms of ascorbate to reduced forms during ascorbate-glutathione cycle by using $\mathrm{NAD}(\mathrm{P}) \mathrm{H}$ and reduced glutathione respectively [9]. Therefore, in the present study, these antioxidant components were selected to study. Two wheat cultivars PBW 644 and PBW 343 contrasting in drought tolerance and ABA-sensitivity [17] were chosen for this study.

\section{MATERIALS AND METHODS}

\section{Plant materials}

Fresh seeds (freshly harvested stored at $-20^{\circ} \mathrm{C}$ ) of wheat (Triticum aestivum L.) cultivars PBW 644 and PBW 343 were used. Seeds were germinated in Petri dishes on sterilized filter paper irrigated with autoclaved distilled water. Plates were kept at 
$4{ }^{\circ} \mathrm{C}$ for $24 \mathrm{~h}$ to break dormancy, grown for 1 day, then treated with chemicals (ABA, PEG, ABA+DMTU/tiron/ PTIO, DMTU/tiron/PTIO and water as CT) for next $1 \mathrm{~d}$ at $25^{\circ} \mathrm{C}$ in the dark, transferred to desiccation chamber for desiccation at room temperature in the presence of saturated solution of $\mathrm{MgCl}_{2}$ as desiccant for $4 \mathrm{~d}$ then rehydrated by transferring to autoclaved sand moistened with autoclaved distilled water for next $4 \mathrm{~d}$ at $25^{\circ} \mathrm{C}$ in the dark [27]. Concentrations of chemicals were $20 \mu \mathrm{M} \mathrm{ABA}, 70 \%$ PEG 6000, $10 \mathrm{mMDMTU}, 10 \mathrm{mM}$ tiron, $50 \mu \mathrm{MPTIO}$. DMTU is N, N'-dimethylthiourea which is specific scavenger of $\mathrm{H}_{2} \mathrm{O}_{2}$. Tiron is sodium 4,5-dihydroxybenzene-1,3-disulfonate which is specific scavenger for superoxide anion radicals. PTIO is 2-phenyl-4, 4,5,5-tetramethylimidazoline-1-oxyl 3-oxide which is specific scavenger for nitric oxide. During the experiment, three stages, $2 \mathrm{~d}$ (before desiccation), $6 \mathrm{~d}$ (desiccated), $10 \mathrm{~d}$ (rehydrated) old seedlings were taken for analysis.

\section{Measurement of contents}

Ascorbate [1] was extracted with ice cold 5\% TCA and measured by incubating extract in $0.053 \% \mathrm{H}_{3} \mathrm{PO}_{4}, 0.004 \% \mathrm{FeCl}_{3}, 0.13 \%$ bathophenanthroline, $60 \%$ ethanol and $2 \%$ TCA at $37{ }^{\circ} \mathrm{C}$ for 1 hour, read at $525 \mathrm{~nm}$. For measurement of total ascorbate, dehydroascorbate was first reduced to ascorbate by incubating extract in $0.015 \%$ DTT, $50 \mathrm{mM}$ sodium hydrogen phosphate, $0.3 \mathrm{M} \mathrm{NaOH}$ for 10 min, adding N-ethylmalemide and TCA to $0.04 \%$ and $3.3 \%$, respectively, then ascorbate was measured by above-mentioned same protocol. Amount was calculated using standard ascorbate ( $50-150 \mathrm{nmole})$. Dehydroascorbate was calculated by subtracting ascorbate value from total ascorbate value.

For hydroxyl radicals [33], tissue was crushed and immersed in $1 \mathrm{mM}$ deoxyribose and incubated at room temperature in the dark with shaking for $45 \mathrm{~min} .0 .5 \mathrm{ml}$ of this extract was added to preheated mixture of $0.5 \mathrm{ml}$ of $1 \%$ TBA in $0.05 \mathrm{M} \mathrm{NaOH}$ and $0.5 \mathrm{ml}$ of $2.8 \%$ TCA. It was immediately boiled for 10 minutes and cooled down on ice for next 10 minutes. Absorbance at $540 \mathrm{~nm}$ was taken and content was calculated in absorbance units.

Malondialdehyde (MDA) [11] was extracted in $1.5 \mathrm{ml}$ of ice-cold $0.1 \%$ TCA, estimated by reacting $1 \mathrm{ml}$ of extract with $4 \mathrm{ml}$ of solution containing $0.5 \%$ TBA in $20 \%$ TCA. Test tubes were incubated at $95{ }^{\circ} \mathrm{C}$ for 30 minutes, cooled down to room temperature, centrifuged and read at $532 \mathrm{~nm}$ and $600 \mathrm{~nm}$. Absorbance at $600 \mathrm{~nm}$ was subtracted from absorbance at $532 \mathrm{~nm}$. The MDA content was calculated by using molar extinction coefficient of MDA of $155 \mathrm{mM}^{-1} \mathrm{~cm}^{-1}$.

\section{Measurement of enzymatic activities}

Monodehydroascorbate reductase (MDHAR) and dehydroascorbate reductase (DHAR) [16] were extracted in $100 \mathrm{mM}$ potassium phosphate buffer ( $\mathrm{pH}$ 7.5) with $1 \mathrm{mM}$ EDTA and 2\% PVP, where $1 \mathrm{mM}$ ascorbate was added before use. MDHAR 
was assayed in $50 \mathrm{mM}$ potassium phosphate buffer (pH 7.5), $10 \mathrm{mM} \mathrm{NaCl}, 2 \mathrm{mM}$ $\mathrm{MgCl}_{2}, 400 \mathrm{mM}$ sucrose, $2.5 \mathrm{mM}$ ascorbate, $0.1 \mathrm{mM}$ NADH and 0.14 units of ascorbate oxidase for disappearance of NADH at $340 \mathrm{~nm}$ at $25^{\circ} \mathrm{C}$ and calculated using $€_{\mathrm{NADH}}$ of $6.22 \mathrm{mM}^{-1} \mathrm{~cm}^{-1}$. DHAR was assayed in $50 \mathrm{mM}$ potassium phosphate buffer ( $\mathrm{pH}$ 7.0), $2.5 \mathrm{mM}$ reduced glutathione (GSH), $0.2 \mathrm{mM}$ dehydroascorbate, 0.1 $\mathrm{mM}$ EDTA for appearance of ascorbate at $265 \mathrm{~nm}$ at $25^{\circ} \mathrm{C}$ and calculated using €asc of $14 \mathrm{mM}^{-1} \mathrm{~cm}^{-1}$.

Alcohol dehydrogenase (AlcDH) [6] was extracted in $0.1 \mathrm{M}$ Tris $\mathrm{HCl}(\mathrm{pH} 9.0)$ with $20 \mathrm{mM} \mathrm{MgCl} 2,0.1 \% \beta$-mercaptoethanol, $1 \mathrm{mM}$ PMSF and assayed in $50 \mathrm{mM}$ Tris $\mathrm{HCl}$ buffer ( $\mathrm{pH} 9.0), 1 \mathrm{mM} \beta$-NAD to which $50 \mu 1$ of ethanol was added to start the reaction at $30{ }^{\circ} \mathrm{C}$ at $340 \mathrm{~nm}$ for production of NADH. Enzyme activity was calculated using $€_{\mathrm{NADH}}$ of $6.22 \mathrm{mM}^{-1} \mathrm{~cm}^{-1}$.

Aldehyde dehydrogenase (AldDH) [6] was extracted in 100 mM HEPES (pH 7.4), $1 \mathrm{mM}$ EDTA, $2 \mathrm{mM}$ DTT and $0.1 \%$ triton-X-100 and assayed with $20 \mu \mathrm{l}$ of enzyme extract in $0.1 \mathrm{M}$ Tris $\mathrm{HCl}$ buffer ( $\mathrm{pH} 9.0), 1.5 \mathrm{mM} \beta$-NAD at $30{ }^{\circ} \mathrm{C}$ at $340 \mathrm{~nm}$ to which $56 \mu 1$ of acetaldehyde was added to start reaction. Change in absorbance was recorded 3 minutes at the interval of 30 seconds. Enzyme activity was calculated using $€_{\mathrm{NADH}}=6.22 \mathrm{mM}^{-1} \mathrm{~cm}^{-1}$.

\section{Statistical analysis}

Three biological replicates were taken for each measurement. Mean \pm S. D. was calculated. Results were analyzed by Duncan Multiple test using DSAASTAT software.

\section{RESULTS}

Data was analyzed in $2 \mathrm{~d}, 6 \mathrm{~d}$ and $10 \mathrm{~d}$-old seedlings where $2 \mathrm{~d}$ stage represented seedlings just before desiccation, $6 \mathrm{~d}$ and $10 \mathrm{~d}$ represented desiccated and rehydrated seedlings, respectively. In figures (Figs 2, 3), data of CT-seedlings was compared among stages and between cultivars; ABA/PEG-treatment was compared to $\mathrm{CT}$ at each stage to check ABA/PEG-improvement. In tables (Tables 1-4), DMTU/tiron/ PTIO was compared to CT, ABA plus DMTU/tiron/PTIO was compared to ABA at each stage to check if endogenous ROS/NO-regulations in CT and ABA-treated seedlings were scavenged in the presence of these chemicals.

\section{Visible observation of growth recovered upon rehydration}

The visual effect of treatments on growth recovered upon rehydration is shown in Fig. 1. Rehydrated growth of PBW 644 was higher with more number of erected seedlings compared to PBW 343 under all conditions, i.e. CT (Fig. 1a, e), ABA (Fig. 1i, m), PEG (Fig. 1q, r). In PBW 343, PEG (Fig. 1r) and ABA (Fig. 1m) treat- 


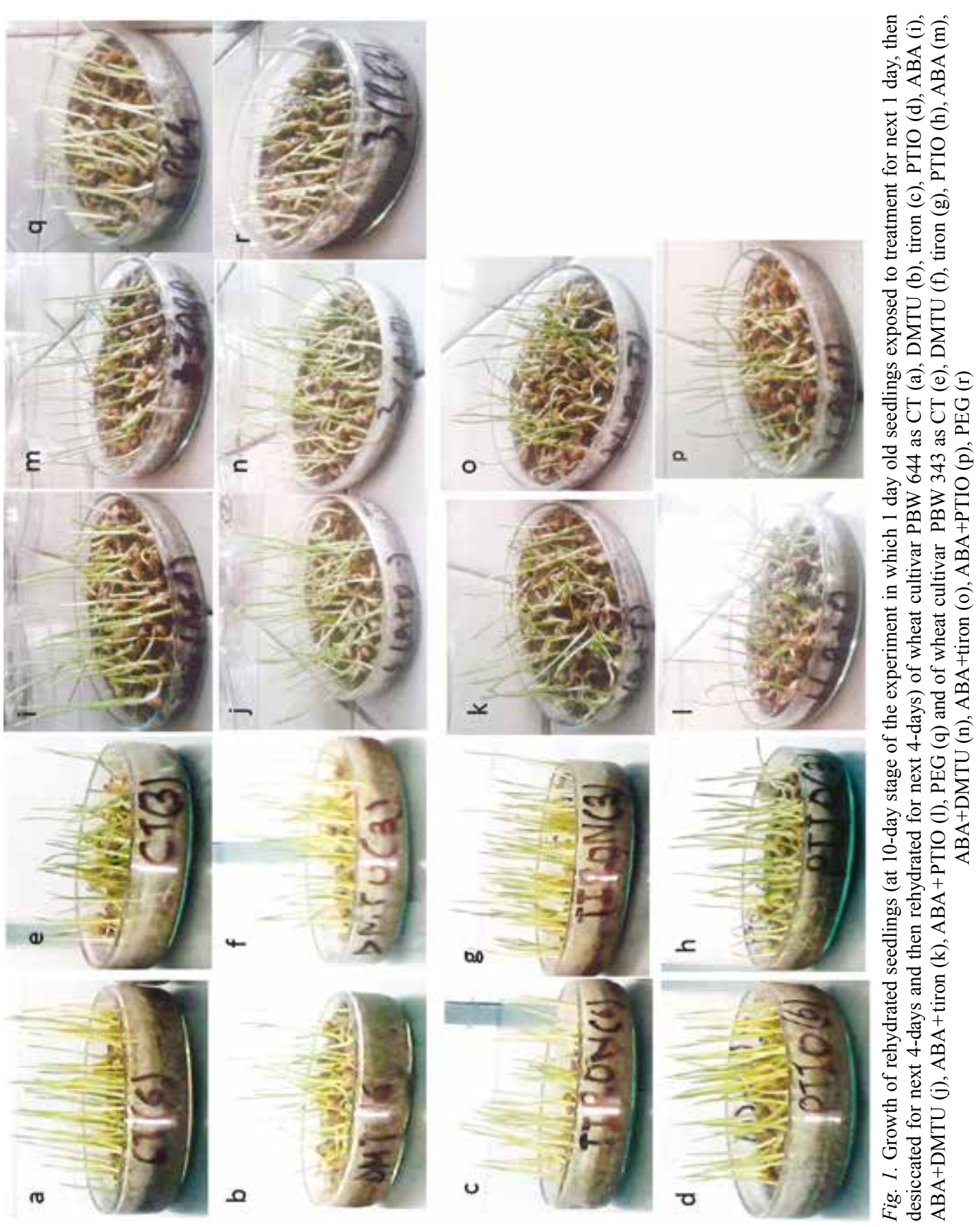




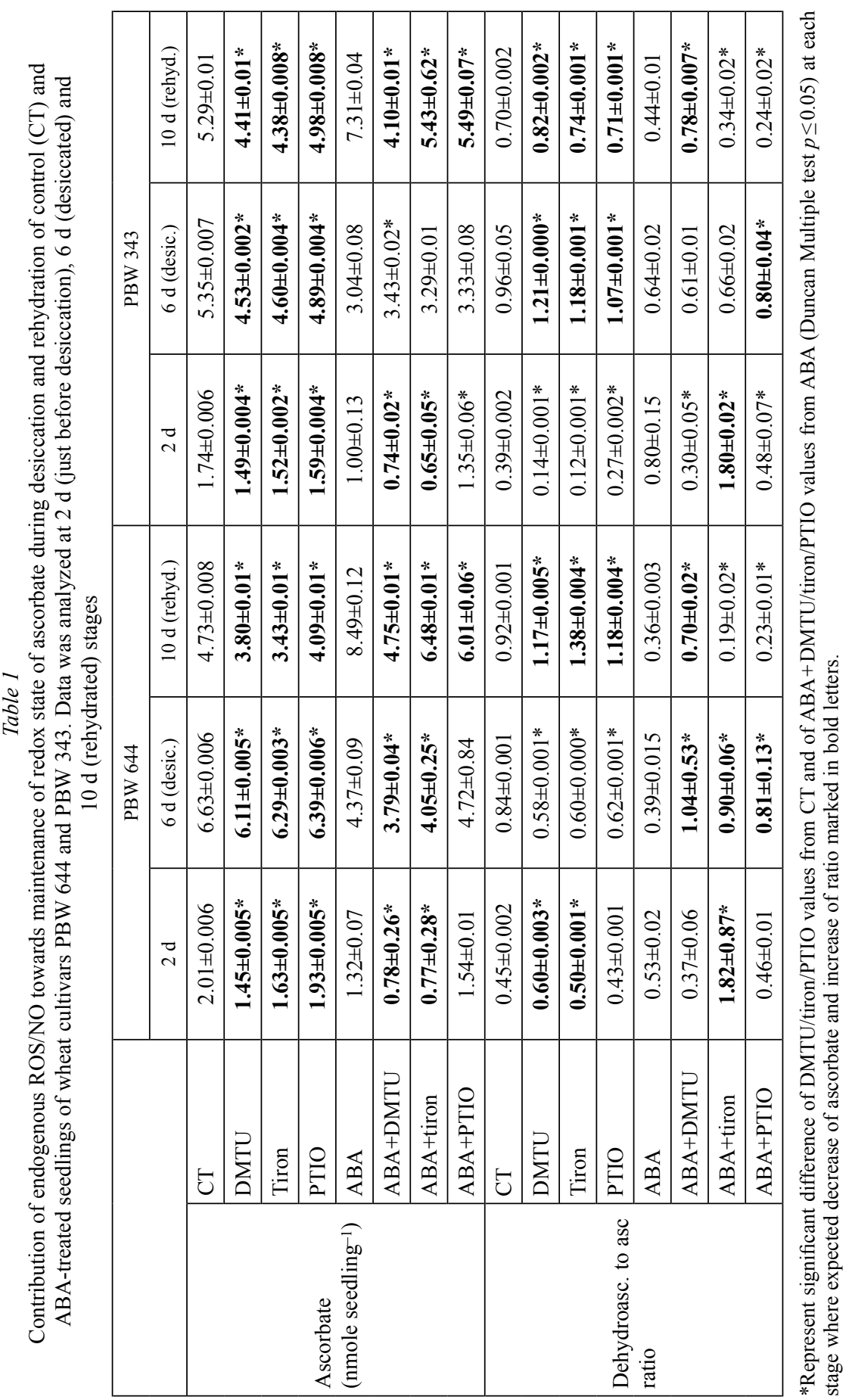


ment improved growth over CT (Fig. 1e). Removal of ROS and NO under CT affected growth in both cultivars but effects were more prominent in PBW 644 (Fig. 1a-d, e-h). Similarly removal of ROS and NO under ABA affected the growth in both cultivars (Fig. 1i-1, m-p).

\section{Redox state of ascorbate}

During desiccation (from $2 \mathrm{~d}$ to $6 \mathrm{~d}$ period), ascorbate content was increased but dehydroascorbate to ascorbate ratio was also increased in both cultivars but increase of ascorbate was higher in PBW 644 (Fig. 2). During rehydration (from $6 \mathrm{~d}$ to $10 \mathrm{~d}$ period), ascorbate content was decreased and ratio remained unaltered in both cultivars. ABA/PEG though decreased ascorbate but also decreased ratio at $6 \mathrm{~d}$, however at $10 \mathrm{~d}, \mathrm{ABA} / \mathrm{PEG}$ increased ascorbate and decreased ratio in both cultivars. Comparing PEG and ABA, improvement was more by ABA. Comparing cultivars, ABA/PEG improvements were more pronounced in PBW 644.

Removal of ROS/NO under CT (Table 1) decreased ascorbate by very significant amount at all three stages in both cultivars. Removal of ROS/NO under ABA decreased ascorbate at $10 \mathrm{~d}$ in both cultivars and $6 \mathrm{~d}$ in PBW 644 only. Removal of ROS/NO under CT increased ratios at $10 \mathrm{~d}$ in both cultivars and at $6 \mathrm{~d}$ in PBW 343 only. Removal of ROS/NO under ABA increased ratio by significant amount at $6 \mathrm{~d}$ in PBW 644 only. Therefore, compared to PBW 343, ABA-signalling contributed more in PBW 644 at $6 \mathrm{~d}$ stage for maintaining redox state of ascorbate.

\section{Oxidative stress (MDA and hydroxyl radicals)}

In CT, MDA (Fig. 2) did not increase from $2 \mathrm{~d}$ to $6 \mathrm{~d}$ period but increased from 6 $\mathrm{d}$ to $10 \mathrm{~d}$ in PBW 644 while in PBW 343, MDA increased by large mount from $2 \mathrm{~d}$ to $6 \mathrm{~d}$ period then decreased from $6 \mathrm{~d}$ to $10 \mathrm{~d}$ period. ABA/PEG did not decrease MDA in both cultivars except ABA decreased it at $6 \mathrm{~d}$ stage in PBW 343, otherwise ABA/PEG were increasing MDA specially in PBW 343. Hydroxyl radicals (Fig. 2) were increased by small amount from $2 \mathrm{~d}$ to $6 \mathrm{~d}$ and by more amount from $6 \mathrm{~d}$ to $10 \mathrm{~d}$ period in both cultivars. ABA/PEG supply increased hydroxyl radicals at all three stages in both cultivars. Levels of hydroxyl radicals remained lower in PBW 644 than PBW 343 under CT/ABA/PEG at all three stages except at $10 \mathrm{~d}$ stage under CT only where level was higher in PBW 644. MDA-pattern appeared as positively related to hydroxyl radicals in PBW 644, but in PBW 343, such relation was not so perfect. ABA/PEG might be increasing ROS and MDA for signal purpose but PBW 644 showed perfect regulation of these molecules due to its antioxidant activity, while PBW 343 due to insufficient level of its antioxidant activity, showed damage.

Removal of ROS/NO under CT (Table 2) increased MDA at $10 \mathrm{~d}$ stage in both cultivars and at $6 \mathrm{~d}$ stage in PBW 644 only. However removal of ROS/NO under ABA 

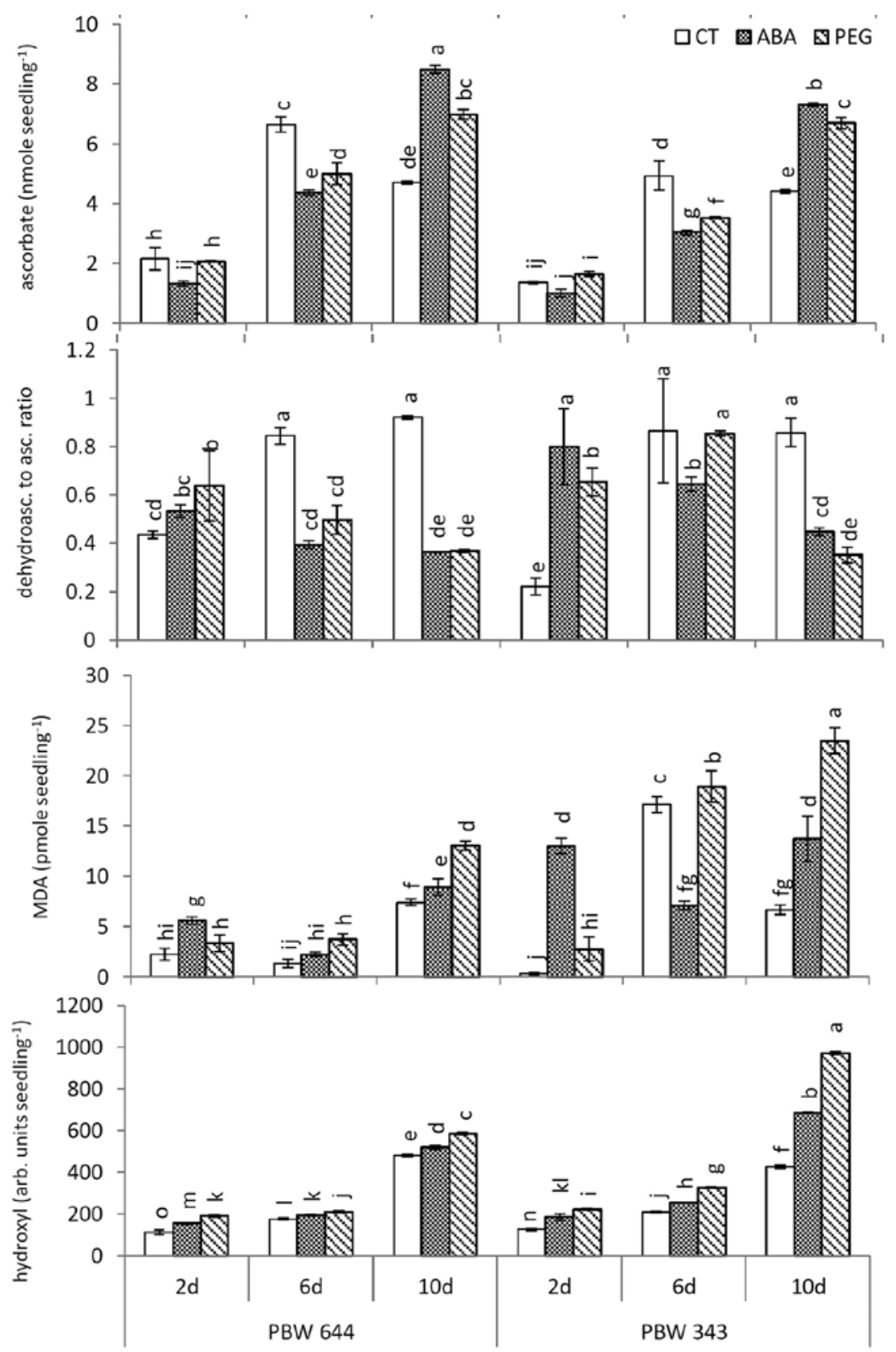

Fig. 2. Change of ascorbate content, dehydroascorbate to ascorbate ratio, malondialdehyde (MDA) and hydroxyl radicals content during desiccation and rehydration of control (CT), ABA, PEG-treated seedlings of two wheat cultivars PBW 644 and PBW 343. One day old seedlings were exposed to ABA, PEG 6000 for next 1 day, desiccated for $4 \mathrm{~d}$, rehydrated for $4 \mathrm{~d}$. Data was taken at $2 \mathrm{~d}$ (just before desiccation), $6 \mathrm{~d}$ (desiccated), $10 \mathrm{~d}$ (rehydrated) old seedlings. Different alphabets represent significant difference (Duncan Multiple test $p \leq 0.05$ ) 


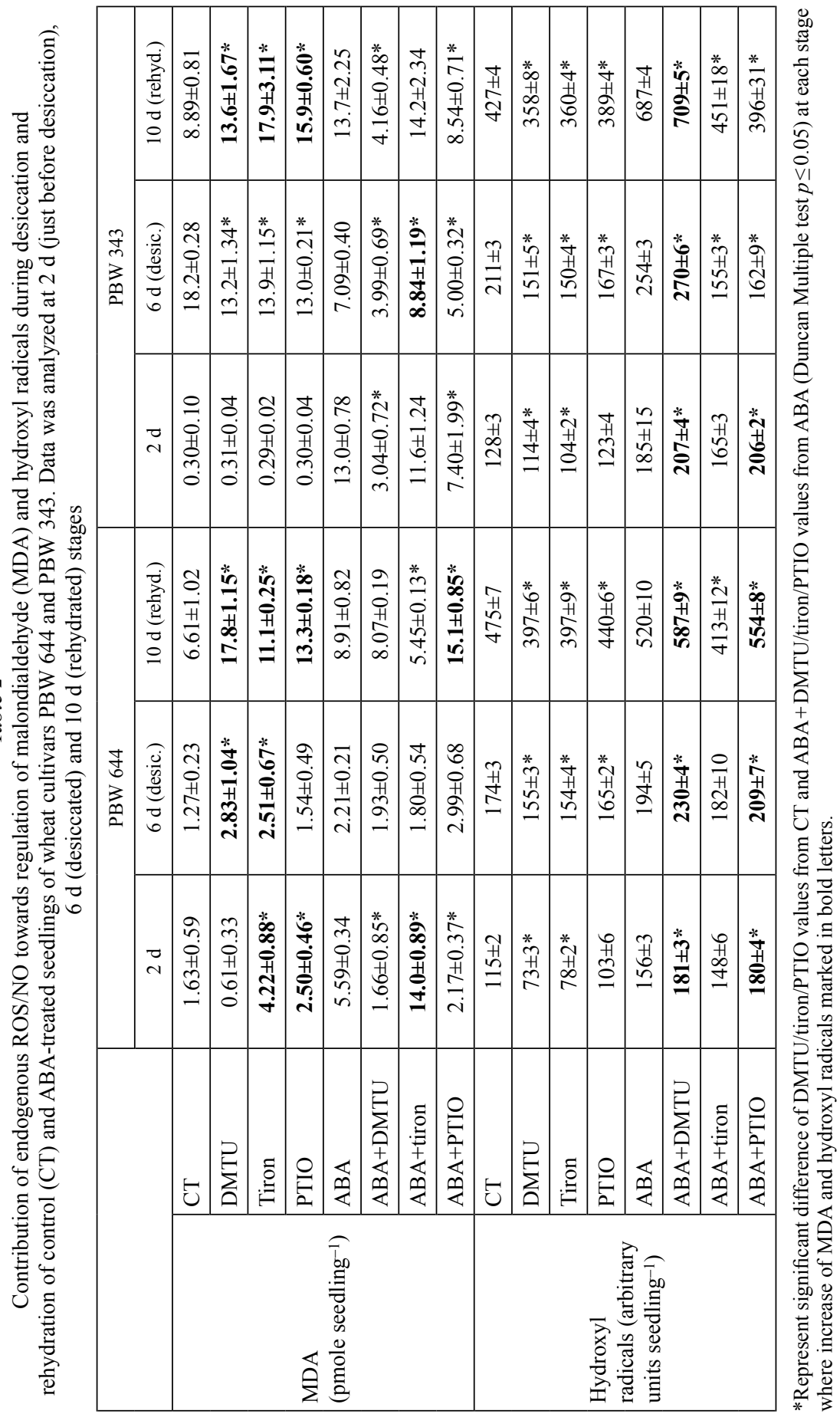



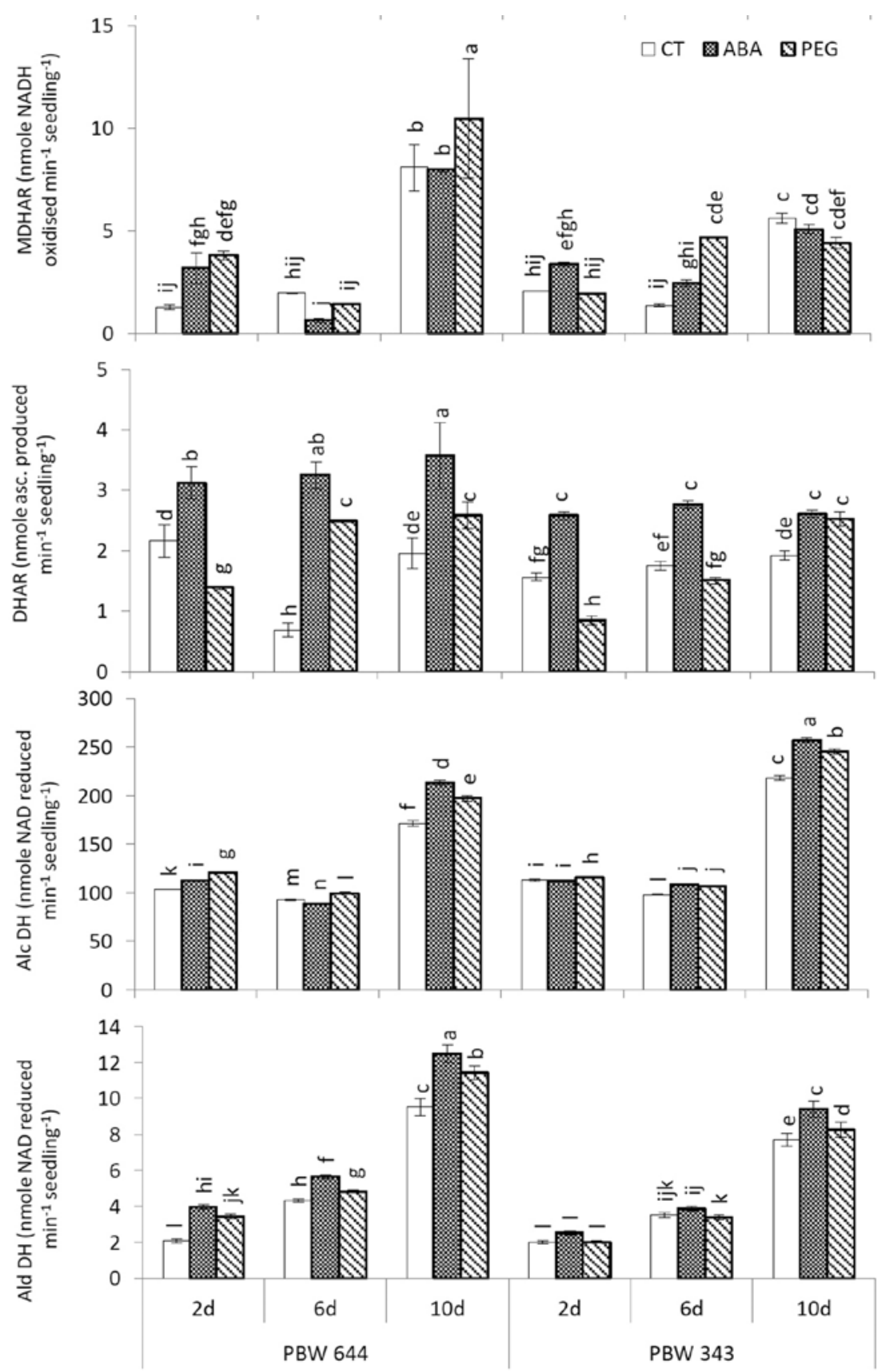

Fig. 3. Change of activities of monodehydroascorbate reductase (MDHAR), dehydroascorbate reductase (DHAR), alcohol dehydrogenase (AlcDH) and aldehyde dehydrogenase (AldDH) during desiccation and rehydration of control (CT), ABA, PEG-treated seedlings of two wheat cultivars PBW 644 and PBW 343.

Rest is same as in Fig. 2 
could not increase MDA effectively in both cultivars. Removal of ROS/NO under CT did not increase hydroxyl radicals rather decreased it while removal of ROS under ABA specially with DMTU increased hydroxyl radicals at all three stages in both cultivars. Both cultivars used ROS/NO signaling in CT plant to control MDA more effectively at $10 \mathrm{~d}$ but PBW 644 used it also at $6 \mathrm{~d}$ where PBW 343 could not, which could be the reason of high increase of MDA at this stage.

\section{MDHAR and DHAR}

MDHAR (Fig. 3) did not alter from $2 \mathrm{~d}$ to $6 \mathrm{~d}$ but increased from $6 \mathrm{~d}$ to $10 \mathrm{~d}$ period in CT of both cultivars, where increase from $6 \mathrm{~d}$ to $10 \mathrm{~d}$ period was higher in PBW 644. DHAR remained unaltered from $2 \mathrm{~d}$ to $10 \mathrm{~d}$ period in PBW 343 but decreased from $2 \mathrm{~d}$ to $6 \mathrm{~d}$ then increased from $6 \mathrm{~d}$ to $10 \mathrm{~d}$ in PBW 644. ABA/PEG improved MDHAR at 2 d, PEG improved it at 10 d in PBW 644 while in PBW 343, only PEG improved it at $6 \mathrm{~d}$. ABA/PEG increased DHAR by very significant amount at $6 \mathrm{~d}$ and $10 \mathrm{~d}$ in PBW 644 while in PBW 343, improvement was seen with only ABA at $6 \mathrm{~d}$, by both $\mathrm{ABA} / \mathrm{PEG}$ at $10 \mathrm{~d}$. Comparing ABA and PEG, increases of DHAR were higher by ABA in both cultivars. Comparing cultivars, ABA/PEG increases of DHAR were higher in PBW 644.

Removal of ROS/NO under CT (Table 3) decreased MDHAR at $2 \mathrm{~d}$ and $6 \mathrm{~d}$ in both cultivars and at $10 \mathrm{~d}$ in PBW 644 only. Removal of ROS/NO under ABA decreased MDHAR at $2 \mathrm{~d}$ and $6 \mathrm{~d}$ in PBW 343 only. Removal of ROS/NO under CT decreased DHAR at $10 \mathrm{~d}$ in PBW 644 and at $6 \mathrm{~d}$ in PBW 343 only. Removal of ROS/NO under ABA decreased DHAR at all three stages in both cultivars. Compared to PBW 644, PBW 343 was poor in using ROS/NO/ABA signaling effectively during rehydration for both MDHAR and DHAR.

\section{AlcDH and AldDH}

In CT, AlcDH (Fig. 3) was decreased by small amount from 2 to $6 \mathrm{~d}$ but increased from 6 to $10 \mathrm{~d}$ in both cultivars. Levels of AlcDH remained slightly higher in PBW 343 at all three stages. ABA/PEG improvement of AlcDH was also seen in both cultivars, but levels of enzyme remained higher in PBW 343. AldDH increased from 2 to 6 and from 6 to $10 \mathrm{~d}$ period in CT of both cultivars but increases were higher in PBW 644. ABA/PEG improvement of AldDH was seen at all three stages in PBW 644 while at $10 \mathrm{~d}$ only in PBW 343. Comparing ABA and PEG, increases of AldDH were higher by ABA in both cultivars. Comparing cultivars, ABA/PEG increases of AldDH were higher in PBW 644.

Removal of ROS specially with DMTU under CT (Table 4) decreased AlcDH at $6 \mathrm{~d}$ and $10 \mathrm{~d}$ in both cultivars. Removal of ROS/NO under ABA decreased AlcDH by significant amount at $10 \mathrm{~d}$ stage in both cultivars. Removal of ROS/NO under CT decreased AldDH mainly at $10 \mathrm{~d}$ stage in both cultivars. Removal of ROS/NO under 


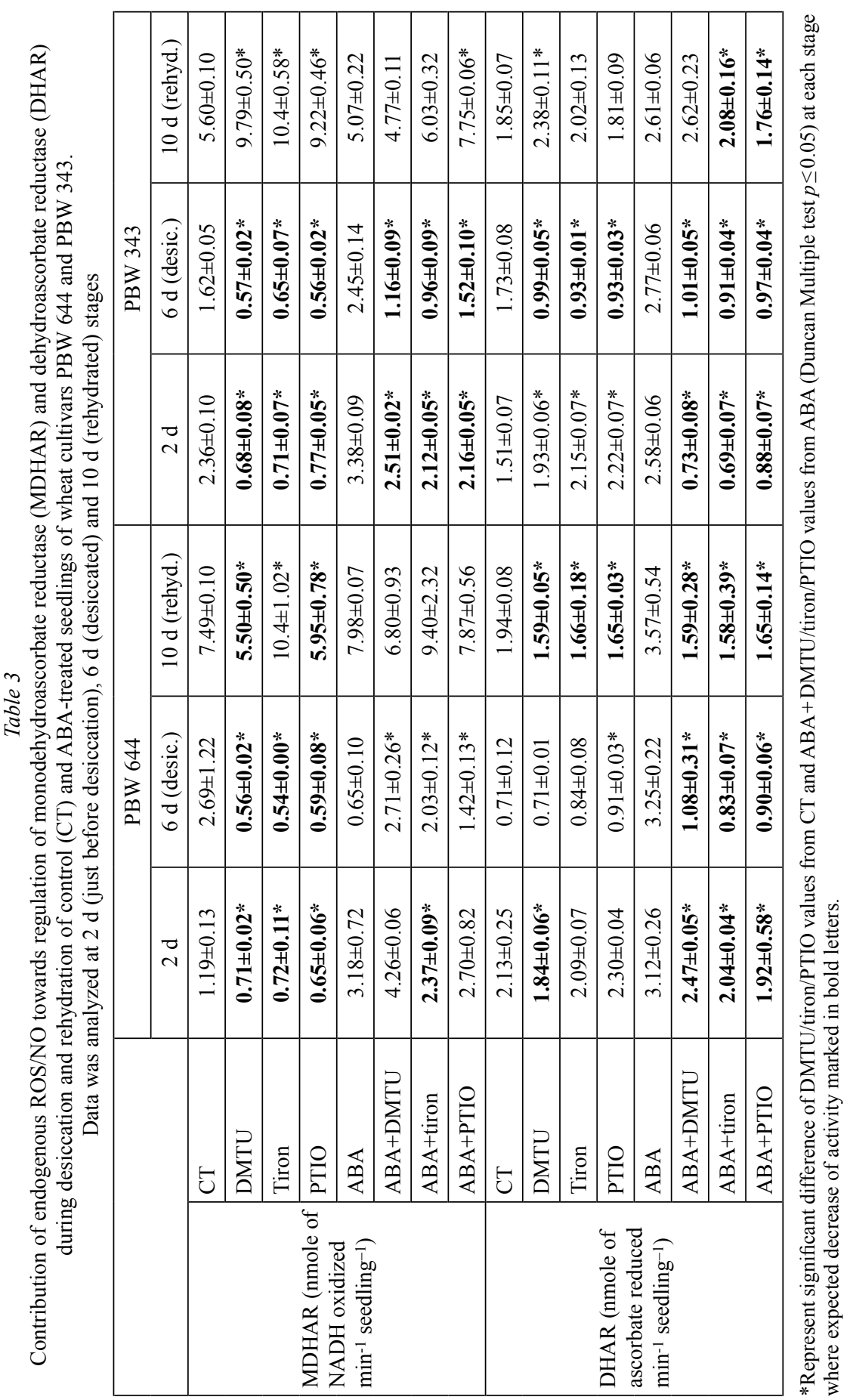


总

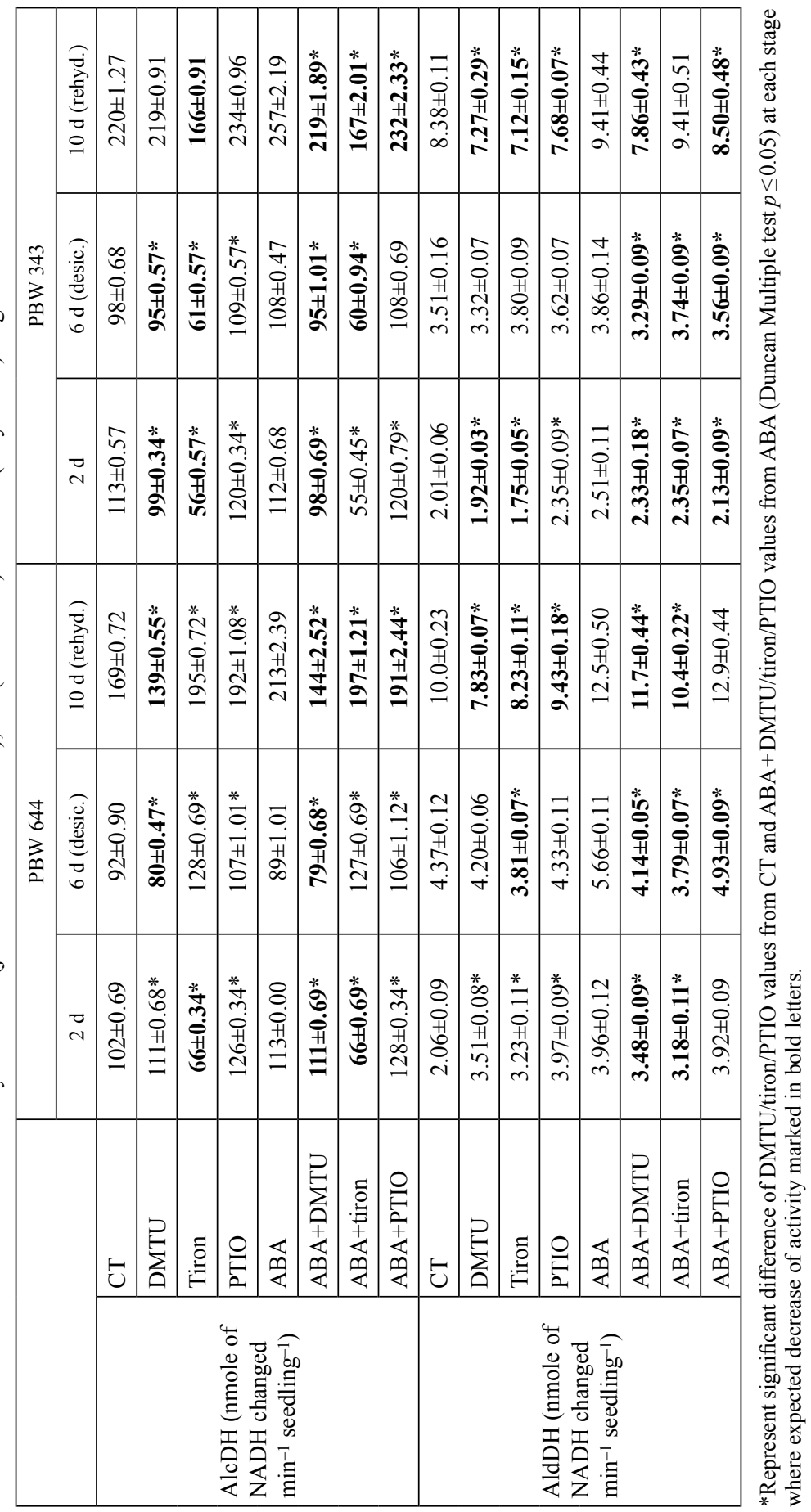


ABA decreased AldDH at 6 and $10 \mathrm{~d}$ in both cultivars. Both cultivars used ROS/NO/ ABA signaling by more amount during rehydration than desiccation to increase AlcDH and AldDH.

\section{DISCUSSION}

Improved growth upon rehydration was an indicator of higher level of post-germination DT. As this was observed higher in drought tolerant cultivar PBW 644 hence post-germination DT could be a good marker for vegetative drought tolerance of the plant. This visual growth data has also been confirmed in dry biomass measurement which is given in detail in our other report [20]. Removal of ROS/NO under CT and $\mathrm{ABA}$ had reduced growth of rehydrated seedlings of almost both cultivars, hence indicated the significant contribution of ROS/NO-pathways in post-germination DT.

Desiccation was not accompanied with increase of antioxidant enzymes tested except aldehyde dehydrogenase and ascorbate content. Both these antioxidants were found higher in PBW 644 than PBW 343, could probably be responsible for observed lesser oxidative toxicity (MDA and hydroxyl radicals) in PBW 644. Increase of ascorbate levels has been found during desiccation of resurrection plants $[8,14]$ and this increase was related to relative water content (RWC) of leaf in Xerophyta viscosa where ascorbate content increased at 65\% RWC but decreased at 35\% RWC [14]. This showed that increase of ascorbate could be similar to as under abiotic/biotic stresses but high water loss might decrease ascorbate. We also found increase of ascorbate during desiccation in control seedlings but ABA/PEG supply decreased this content. These supplies also caused more water-loss and growth arrest [20]. Therefore, $\mathrm{ABA} / \mathrm{PEG}$ could decrease ascorbate for improving desiccation tolerance as ascorbate besides acting as antioxidant, stimulates cell division and cell expansion [15]. In orthodox seeds, low levels of ascorbate have been related to desiccation tolerance [41]. ABA-pathway mediated through ABI4 can reduce ascorbate to induce growth arrest [18].

ABA/PEG supply though decreased ascorbate during desiccation but regulate dehydroascorbate to ascorbate ratio effectively through increasing DHAR activity. Studies $[10,16,34]$ have indicated differential regulation of MDHAR and DHAR where MDHAR plays role under moderate stress while DHAR is induced when ascorbate content declines or dehydroascorbate content increases. In the present study, DHAR was not induced in control seedlings but ABA/PEG supply increased this enzyme by manyfold during desiccation and decreased the ascorbate content.

Aldehyde dehydrogenase is also related to desiccation tolerance in resurrection plants as it detoxifies toxic aldehydes like malondialdehyde, acetaldehyde, propionaldehyde [19, 31, 35]. Transgenic Arabidopsis plants overexpressing AtAldDH 3 gene showed tolerance to dehydration and low accumulation of malondialdehyde $[4,38]$.

Though antioxidant enzymes did not increase during desiccation but ABA/ROS/ NO-pathways were involved to maintain antioxidant activity. These pathways are 
involved in activation of antioxidant potential of plants under vegetative stresses [30]. We found involvement of these pathways in post-desiccation tolerance, too.

Contrary to desiccation, rehydration as a process of growth revival was accompanied with high increase of antioxidant content including ascorbate and enzymes. $\mathrm{ABA} / \mathrm{ROS} / \mathrm{NO}$-pathways contributed more to maintain antioxidant content specially MDHAR and DHAR during rehydration than desiccation. ABA increases of ascorbate and antioxidant enzymes were much higher during rehydration than during desiccation. Antioxidants during rehydration are more important than during desiccation as rehydration is a shift from metabolic arrest to metabolic active state, it is accompanied with increase of ROS, tissues deficient in antioxidants mostly fails to revert back [3, 21, 39].

Though response of both cultivars towards desiccation and rehydration and its ABA-regulation was almost same but antioxidant content and ABA-upregulations were higher in PBW 644. This cultivar difference was more pronounced during rehydration in both control and ABA/PEG-treated seedlings. It is widely accepted that most dramatic period of oxidative injury occurs when plant rehydrates after a period of dehydration. It is due to inability of enzymatic antioxidative system to buffer water, which leads to uncontrolled free radical chain reactions [37, 39]. However, desiccation tolerant plants were found to possess unique antioxidants which gain full activity within small time period of rehydration [37,39], for example, in resurrection plant Myrothamnus abellifolia [21], redox shift of ascorbate and glutathione occurred towards oxidized forms during desiccation but rehydration induced reduced forms of these antioxidants with simultaneous reduction of their oxidised forms.

In the present study, PEG resembled to ABA for its effects, hence might mediate its effects through endogenous ABA-pathways. We have also applied $300 \mathrm{mM} \mathrm{NaCl}$ as salt stress and $40{ }^{\circ} \mathrm{C}$ as heat stress similar to as applied PEG in the same experiment (results not shown), found almost similar effects in all stresses and ABA. This showed that antioxidant regulation during post-germination desiccation and rehydration could be the mechanism of ABA-regulated cross-tolerance.

In summary, that post-germination desiccation tolerance in wheat was accompanied with increase of oxidative stress and some special antioxidants (ascorbate and aldehyde dehydrogenase). Higher desiccation tolerance was related to higher increase of such special antioxidants and less oxidative stress. During rehydration, antioxidant machinery had contributed by significant amount to detoxify ROS. During desiccation and rehydration, ROS/NO/ABA-pathways had contributed to maintain antioxidant machinery. High amount of ABA during desiccation might decrease ascorbate.

\section{REFERENCES}

1. Arakawa, N., Tsutsumi, K., Sanceda, N. G., Kurata, T., Inagaki, C. (1981) A rapid and sensitive method for the determination of ascorbic acid using 4,7-Diphenyl-1,10-phenanthroline. Agric. Biol. Chem. 45, 1289-1290.

2. Dekkers, B. J. W., Costa, M. C. D., Maia, J., Bentsink, L., Ligterink, W., Hilhorst, H. W. M. (2015) Acquisition and loss of desiccation tolerance in seeds: from experimental model to biological relevance. Planta 241, 563-577. 
3. Dinakar, C., Bartels, D. (2012) Light response, oxidative stress management and nucleic acid stability in closely related Linderniaceae species differing in desiccation tolerance. Planta 236, 541-555.

4. Dinakar, C., Bartels, D. (2013) Desiccation tolerance in resurrection plants: new insights from transcriptome, proteome, and metabolome analysis. Front. Plant Sci. 4, e482.

5. Fujii, H., Verslues, P. E., Zhu, J. K. (2007) Identification of two protein kinases required for abscisic acid regulation of seed germination, root growth, and gene expression in Arabidopsis. Plant Cell 19, 485-494.

6. Fukao, T., Kennedy, R. A., Yamasue, Y., Rumpho, M. E. (2003) Genetic and biochemical analysis of anaerobically-induced enzymes during seed germination of Echinochloa crus-galli varieties tolerant and intolerant of anoxia. J. Exp. Bot. 54, 1421-1429.

7. Gaff, D. F., Oliver, M. (2013) The evolution of desiccation tolerance in angiosperm plants: a rare yet common phenomenon. Funct. Plant Biol. 40, 315-328.

8. Gechev, T. S., Benina, M., Obata, T., Tohge, T., Sujeeth, N., Minkov, I., Hille, J., Temanni, M.-R., Marriott, A. S., Bergstrom, E., Thomas-Oates J., Antonio, C., Mueller-Roeber, B., Schippers, J. H. M., Fernie, A. R., Toneva, V. (2013) Molecular mechanisms of desiccation tolerance in the resurrection glacial relic Haberlea rhodopensis. Cell. Mol. Life Sci. 70, 689-709.

9. Gill, S. S., Tuteja, N. (2010) Reactive oxygen species and antioxidant machinery in abiotic stress tolerance in crop plants. Plant Physiol. Biochem. 48, 909-930.

10. Haroldsen, V. M., Chi-Ham, C. L., Kulkarni, S., Lorence, A., Bennett, A. B. (2011) Constitutively expressed DHAR and MDHAR influence fruit, but not foliar ascorbate levels in tomato. Plant Physiol. Biochem. 49, 1244-1249.

11. Heath, R. L., Packer, L. (1968) Photoperoxidation in isolated chloroplasts. I. kinetics and stoichiometry of fatty acid peroxidation. Arch. Biochem. Biophys. 125, 180-198.

12. Hossain, M. A., Bhattacharjee, S., Armin, S.-M., Qian, P., Xin, W., Li, H.-Y., Burritt, D. J., Fujita, M., Tran, L.-SP. (2015) Hydrogen peroxide priming modulates abiotic oxidative stress tolerance: insights from ROS detoxification and scavenging. Front. Plant Sci. 6, e420.

13. Huang, H., Song, S. (2013) Change in desiccation tolerance of maize embryos during development and germination at different water potential PEG-6000 in relation to oxidative process. Plant Physiol. Biochem. 68, 61-70.

14. Ingle, R. A., Schmidt, U. G., Farrant, J. M., Thomson, J. A., Sagadevan, G., Mundree, S. G. (2007) Proteomic analysis of leaf proteins during dehydration of the resurrection plant Xerophyta viscosa. Plant Cell Environ. 30, 435-446.

15. Jubany-Mari, T., Munne-Bosch, S., Alegre, L. (2010) Redox regulation of water stress responses in field-grown plants. Role of hydrogen peroxide and ascrobate. Plant Physiol. Biochem. 48, 351-358.

16. Kaur, L., Gupta, A. K., Zhawar, V. K. (2014) ABA improvement of antioxidant metabolism under water stress in two wheat cultivars contrasting in drought tolerance. Indian J. Plant Physiol. 19, $189-196$.

17. Kaur, R., Zhawar, V. K. (2017) Hydrogen peroxide and nitric oxide regulation of phenolic metabolism under water stress and ABA in wheat. Acta Biol. Hung. 68, 162-174.

18. Kerchev, P. I., Pellny, T. K., Vivancos, P. D., Kiddle, G., Hedden, P., Driscoll, S., Vanacker, H., Verrier, P., Hancock, R. D., Foyer, C. H. (2011) The transcription factor ABI4 is required for the ascorbic acid-dependent regulation of growth and regulation of jasmonate-dependent signaling pathways in Arabidopsis. Plant Cell 23, 3319-3334.

19. Kirch, H. H., Nair, A., Bartels, D. (2001) Novel ABA- and dehydration-inducible aldehyde dehydrogenase genes isolated from the resurrection plant Craterostigma plantagineum and Arabidopsis thaliana. Plant J. 28, 555-567.

20. Kour, S., Zhawar, V. K. (2018) ABA regulation of post-germination desiccation tolerance in wheat cultivars contrasting in drought tolerance. An. Acad. Bras. Cienc. (Accepted)

21. Kranner, I., Richard, P., Beckett, R. P., Wornik, S., Zorn, M., Pfeifhofer, H. W. (2002) Revival of a resurrection plant correlates with its antioxidant status. Plant J. 31, 13-24.

22. Leprince, O., Buitink, J. (2010) Introduction to desiccation biology: from old borders to new frontiers. Planta 242, 369-378. 
23. Lopez-Molina, L., Mongrand, S., Kinoshita, N., Chua, N. H. (2003) AFP is a novel negative regulator of ABA signalling that promotes ABI5 protein degradation. Genes Dev. 17, 410-418.

24. Lopez-Molina, L., Mongrand, S., McLachlin, D. T., Chait, B. T., Chua, N. H. (2002) ABI5 acts downstream of ABI3 to execute an ABA-dependent growth arrest during germination. Plant J. 32, 317-328.

25. Lopez-Molina, L., Mongrand. S., Chua, N. H. (2001) A postgermination developmental arrest checkpoint is mediated by abscisic acid and requires the ABI5 transcription factor in Arabidopsis. Proc. Natl Acad. Sci. 98, 4782-4787.

26. Lyall, R., Ingle, R. A., Illing, N. (2014) The window of desiccation tolerance shown by early stage germination seedlings remains open in the resurrection plant, Xerophyta viscosa. PLoS ONE 9, e93093.

27. Maia, J., Dekkers, B. J. W., Provart, N. J., Ligterink, W., Hilhorst, H. W. M. (2011) The re-establishment of desiccation tolerance in germinated Arabidopsis thaliana seeds and its associated transcriptome. PLoS ONE 6, e29123.

28. Maia, J., Dekkers, B. J., Dolle, M. J., Ligterink, W., Hilhorst, H. W. (2014) Abscisic acid (ABA) sensitivity regulates desiccation tolerance in germinated Arabidopsis seeds. New Phytol. 203, 81-93.

29. Masetto, T. E., Faria, J. M., Fraiz, A. C. R. (2014) Re-induction of desiccation tolerance after germination of Cedrela fissilis Vell. seeds. An. Acad. Bras. Cienc. 86, 1273-1285.

30. Miller, G., Suzuki, N., Sultan, C. Y., Mittler, R. (2010) Reactive oxygen species homeostasis and signalling during drought and salinity stress. Plant Cell. Environ. 33, 453-467.

31. Moore, J. P., Le, N. T., Brandt, W. F., Driouich, A. Farrant, J. M. (2009) Towards a systems-based understanding of plant desiccation tolerance. Trends Plant. Sci. 14, 110-117.

32. Nedeva, D., Nikolova, A. (1997) Desiccation tolerance in developing seeds. Bulg. J. Plant Physiol. $23,100-113$.

33. Omoto, E., Nagao, H., Taniguchi, M., Miyake, H. (2013) Localization of reactive oxygen species and change of antioxidant capacities in mesophyll and bundle sheath chloroplasts of maize under salinity. Plant Physiol. 149, 1-12.

34. Perez-Lopez, U., Robredo, A., Lacuesta, M., Sgherri, C., Munoz-Rueda, A., Navari-Izzo, F., MenaPetite, A. (2009) The oxidative stress caused by salinity in two barley cultivars is mitigated by elevated $\mathrm{CO}_{2}$. Physiol. Plant. 135, 29-42.

35. Rodriguez, M. C. S., Edsgard, D., Hussain, S. S., Alquezar, D., Rasmussen, M., Gilbert, T., Nielsen, B. H., Bartels, D., John Mundy, J. (2010) Transcriptomes of the desiccation-tolerant resurrection plan Craterostigma plantagineum. Plant J. 63, 212-228.

36. Santisree, P., Bhatnagar-Mathur, P., Sharma, K. K. (2015) NO to drought-multifunctional role of nitric oxide in plant drought: Do we have all the answers? Plant Sci. 239, 44-55.

37. Sgherri, C., Stevanovic, B., Navari-Izzo, F. (2004) Role of phenolic acid during dehydration and rehydration of Ramonda serbica. Physiol. Plant. 122, 478-485.

38. Sunkar, R., Bartels, D., Kirch, H. H. (2003) Overexpression of a stress-inducible aldehyde dehydrogenase gene from Arabidopsis thaliana in transgenic plants improves stress tolerance. Plant. J. $35,452-464$.

39. Veljovic-Jovanovic, S., Kukavica, B., Navari-Izzo, F. (2008) Characterization of polyphenol oxidase changes induced by desiccation of Ramonda serbica leaves. Physiol. Plant. 132, 407-416.

40. Vieira, C. V., Amaral da Silva, E. A., de Alvarenga, A. A., de Castro, E. M., Toorop, P. E. (2010) Stress-associated factors increase after desiccation of germinated seeds of Tabebuia impetiginosa Mart. Plant Growth. Regul. 62, 257-263.

41. Weitbrecht, K., Muller, K., Leubner-Metzger, G. (2011) First off the mark: early seed germination. J. Exp. Bot. 62, 3289-3309. 